\title{
Bioequivalence of Final Tablet \\ Formulation and Research Tablet Formulation of Eslicarbazepine Acetate in Healthy Volunteers
}

\author{
Ricardo Lima1, Teófilo Vasconcelos', Rui Cerdeira', Marc Lefebvre², \\ Eric Sicard ${ }^{2}$, Teresa Nunes ${ }^{1}$, Luis Almeida1, Patrício Soares-da-Silva ${ }^{1, \star}$ \\ ${ }^{1}$ BIAL - Portela \& C ${ }^{a}$, SA, S. Mamede do Coronado, Portugal \\ ${ }^{2}$ Algorithme Pharma Inc, Montreal, Québec, Canada
}

\begin{abstract}
Purpose: To investigate the bioequivalence of the final tablet formulation of eslicarbazepine acetate (ESL) and the tablet formulation used in pivotal clinical studies.

Methods: Single centre (Algorithme Pharma, Quebec, Canada) study consisting of three single-dose, randomized, two-way crossover sub-studies in healthy subjects. In each sub-study $(n=20)$, the bioavailability of BIA 2005 (ESL active metabolite) following a given ESL tablet strength (400 mg, $600 \mathrm{mg}$ or $800 \mathrm{mg}$ ) of the final formulation (Test) was compared with the corresponding tablet strength of the research formulation (Reference), under fasting conditions. The statistical method for testing bioequivalence was based upon the $90 \%$ confidence interval $(90 \% \mathrm{CI})$ for the Test/Reference geometric mean ratio (GMR) for $\mathrm{C}_{\max }, \mathrm{AUC}_{0-\mathrm{t}}$ and $\mathrm{AUC}_{0-\infty}$. Bioequivalence was to be assumed when the $90 \% \mathrm{CI}$ fell within the recommended acceptance interval $80.00 \% ; 125.00 \%$.
\end{abstract}

Results: The Test/Reference GMR and 90\%CI for BIA 2-005 were as follows: $400 \mathrm{mg}$ tablets - 105.37\% (99.57\%; $111.52 \%), 102.83(99.19 \% ; 106.61 \%)$ and $102.83 \%$ $(99.13 \% ; 106.66 \%)$ for $\mathrm{C}_{\max }, \mathrm{AUC}_{0-\mathrm{t}}$ and $\mathrm{AUC}_{0-\infty}$, respectively; $600 \mathrm{mg}$ tablets $-102.65 \%(97.27 \%$; $108.33 \%)$, $102.40 \%(99.00 \% ; 105.93 \%)$ and $102.38 \%$ (98.97\%; $105.90 \%$ ) for $\mathrm{C}_{\max }, \mathrm{AUC}_{0-\mathrm{t}}$ and $\mathrm{AUC}_{0-\infty}$, respectively; 800 mg tablets - 104.16\% (95.44\%; $113.67 \%), 100.34 \%$ $(97.85 \% ; 102.90 \%)$ and $99.88 \%(97.65 \% ; 102.16 \%)$ for $\mathrm{C}_{\max }, \mathrm{AUC}_{0-\mathrm{t}}$ and $\mathrm{AUC}_{0-\infty}$, respectively.

Conclusion: The $90 \% \mathrm{CI}$ of all pharmacokinetic parameters of interest $\left(\mathrm{C}_{\max }, \mathrm{AUC}_{0-\mathrm{t}}\right.$, and $\left.\mathrm{AUC}_{0-\infty}\right)$ fell within the acceptance range of $80.00 \% ; 125.00 \%$. Therefore, bioequivalence of the final tablet formulation and the tablet formulation used in the pivotal clinical trials of ESL has been demonstrated.

Keywords: Eslicarbazepine acetate; Bioequivalence; Final tablet formulation; Research formulation

\section{Introduction}

Eslicarbazepine acetate (ESL; (S)-10-acetoxy-10,11-dihydro$5 \mathrm{H}$-dibenz[b,f]azepine-5-carboxamide) is a new generation voltage-gated sodium channel (VGSC) blocker. It has completed Phase III clinical trials as adjunctive therapy in partial epilepsy in adults and is currently undergoing Phase III studies as ad- junctive therapy in children. Other ongoing studies include Phase II in neuropathic pain, prevention of migraine and fibromyalgia.

ESL is chemically related with carbamazepine and oxcarbazepine, as all three share the dibenzazepine nucleus, but is structurally different at the 10,11-position, fact that successfully avoids the production of toxic metabolites - unlike carbamazepine, ESL is not metabolized to carbamazepine epoxide (CBZ-E) - and overcomes enantiomeric impurity and production of enantiomers or diastereoisomers of metabolites and conjugates without losing pharmacological activity (Benes et al., 1999). Moreover, a study using the research formulation has shown that ESL pharmacokinetics is not affected by the presence of food (Maia et al., 2005), allowing a wider label on what concerns time for drug intake. Dosage form proportionality and absence of food-effect of ESL final tablet formulation has been, as well, demonstrated in another clinical study (unpublished data).

Studies in humans, using a chiral method for the assessment of plasma drug concentrations, have shown that ESL is rapidly and extensively converted to eslicarbazepine following oral administration (Almeida et al., 2005). Thus ESL is a prodrug to eslicarbazepine, which is the major metabolite responsible for the therapeutic effect. Plasma levels of parent drug (ESL) are usually undetectable. In the present study an achiral method was used, thus not allowing to separate between eslicarbazepine and its minor metabolite $(R)$-licarbazepine, and, in such cases, the mixture is reported as BIA 2-005 (Almeida and Soares-da-Silva, 2003; Almeida and Soares-da-Silva, 2003).

Throughout the clinical development of ESL several oral formulations have been developed. This was due to the need of having a double-blind design in several placebo-controlled studies, as well as to make available appropriate dosage forms for particular populations, such as children and adults with swallowing difficulties. A preliminary study has demonstrated *Corresponding author: Professor Patricio Soares-da-Silva, Department
of Research \& Development, BIAL, À Av. da Siderurgia Nacional, 4745-
457 S. Mamede do Coronado, Portugal, Tel: +351-229866100, Fax: +351-
229866192 , E-mail: psoares.silva@bial.com
Received July 30, 2009; Accepted October 24, 2009; Published Octo-
ber 24, 2009
Citation: Lima R, Vasconcelos T, Cerdeira R, Lefebvre M, Sicard E, et
al. (2009) Bioequivalence of Final Tablet Formulation and Research Tablet
Formulation of Eslicarbazepine Acetate in Healthy Volunteers. J Bioequiv
Availab 1: 093-098. doi:10.4172/jbb.1000014
Copyright: @ 2009 Lima R, et al. This is an open-access article distrib-
uted under the terms of the Creative Commons Attribution License, which
permits unrestricted use, distribution, and reproduction in any medium,
provided the original author and source are credited. 


\section{Journal of Bioequivalence \& Bioavailability - Open Access \\ JBB/Vol.1 September-October 2009}

that the pharmacokinetic profiles of ESL $50 \mathrm{mg} / \mathrm{mL}$ oral suspension, $200 \mathrm{mg}$ tablet (low strength, easy to swallow) and $800 \mathrm{mg}$ tablet formulations were essentially similar, being the different formulations considered bioequivalent (Fontes-Ribeiro et al., 2005). Considering that some changes in components and composition, from the research to the final formulation, were performed prior to approval, bioequivalence was required to be demonstrated.

The present study aimed to provide information on the bioequivalence between the ESL $400 \mathrm{mg}, 600 \mathrm{mg}$ and $800 \mathrm{mg}$ tablet strengths of the research formulations used in the pivotal clinical studies and the final formulation planned for marketing. The different tablets from this last formulation are considered to be homothetic, as those have the same qualitative and quantitative composition, only varying the tablet mass. Following the applicable regulatory guidelines (EMEA/CPMP, 2001; FDA/CDER, 2000), comparative in vitro dissolution studies have also been performed, in order to demonstrate equivalence between the dissolution profiles for the formulations under study.

\section{Methods}

\section{Study Design}

The present study consisted of three single-dose, randomized, two-way crossover sub-studies in healthy subjects, balanced by gender, and was performed at a single centre (Algorithme Pharma, Quebec, Canada). In each sub-study $(n=20)$, the bioavailability of the active metabolite, following a given ESL tablet strength (400 mg, $600 \mathrm{mg}$ or $800 \mathrm{mg}$ ) of the final formulation (Test), was compared with the corresponding tablet strength of the research formulation (Reference), under fasting conditions. The investigational medicinal products (IMP) were administered to sixty (60) healthy male and female volunteers. The trial consisted of two periods (Period 1 and Period 2) during which participants were administered a single oral $400 \mathrm{mg}$, $600 \mathrm{mg}$ or $800 \mathrm{mg}$ dose of ESL, either Test or Reference, depending on the treatment sequence. Following the cross-over design, subjects having the Test IMP in Period 1 were given the Reference IMP in Period 2 and the ones having Reference IMP in Period 1 were gave the Test IMP in Period 2. The wash-out period was of at least 7 days, corresponding to more than 10 times the expected half-life of the moieties to be measured. In each period, subjects were to arrive at the clinical site at least 10 hours before dosing. After a supervised overnight fast, a single oral dose of the assigned formulation was to be orally administered in the morning, together with approximately $240 \mathrm{~mL}$ of potable water. Meals were provided no less than 4 hours after drug administration. Water was allowed ad libitum until 2 hours pre-dose and 2 hours after drug administration. Subjects were allowed to leave the clinical site after the 24-hour post-dose blood draw and were asked to return to the clinical site before each of the remaining blood samples. Blood samples were collected, prior to and $0.5,1,1.5,2,2.5,3,3.5,4,6,9,12,24,48$ and 72 hours after drug administration, into pre-cooled heparin lithium Vacutainers. As soon as possible following blood collection, samples were centrifuged at a temperature of $4{ }^{\circ} \mathrm{C}$ nominal and at $1500 \mathrm{~g}$ for 10 minutes. The plasma samples obtained were frozen and kept at $-20{ }^{\circ} \mathrm{C}$ until sent on dry ice to the laboratory responsible for the assay.

Reference IMP (ESL immediate release $400 \mathrm{mg}, 600 \mathrm{mg}$ and
$800 \mathrm{mg}$ tablets, research formulations) was manufactured by BIAL (S. Mamede do Coronado, Portugal) and Test IMP (ESL immediate release $400 \mathrm{mg}, 600 \mathrm{mg}$ and $800 \mathrm{mg}$ tablets, final formulation) was manufactured by PATHEON (Toronto, Canada), both in full compliance with the principles of the Good Manufacturing Practice.

The clinical study was conducted according to the principles of the Declaration of Helsinki and the Good Clinical Practice. The protocol and the informed consent forms were approved by an Institutional Review Board (ETHIPRO, Montreal, Quebec, Canada), prior to the study start.

\section{Study Population}

Participants enrolled were healthy male or female volunteers aged between 18 and 55 years, with a body mass index between 19 and $29.99 \mathrm{~kg} / \mathrm{m}^{2}$, non-smokers, smokers of less than 10 cigarettes or equivalent per day for at least 3 months before day 1 of the study or ex-smokers who completely stopped smoking for at least 12 months before day 1 of this study. Eligible female subjects were not considered to be of childbearing potential (females who have had a hysterectomy or tubal ligation, are clinically diagnosed infertile or are in a menopausal state) or were required to take appropriate measures to prevent pregnancy during the study, such as total abstinence or the use of an approved contraceptive regimen. Beside enzyme-modifying drugs that were not allowed for 28 days prior to dosing, systemic contraceptives (injections) and hormonal replacement therapy which were not allowed for 13 weeks prior to dosing, participants were required not to take any prescription medications for 14 days prior to dosing and during the study and any over-the-counter (OTC) products for 7 days prior to dosing and during the study.

Of the sixty healthy male and female subjects who were included in the study, 59 subjects completed the crossover design and received a single oral dose of the assigned formulation on day 1 and day 8 . One of the subjects was withdrawn after dosing of period 1 for pharmacokinetic reasons and received only one single oral dose of ESL. Fifty-nine subjects (30 males and 29 females) were, therefore, analyzed and included in the statistical analysis.

\section{Assay of ESL and BIA 2-005 Concentrations in Plasma}

Plasma concentrations of ESL and BIA 2-005 were determined using high performance liquid chromatography (HPLC) with mass spectrometric detection (MS). ESL stock solution (100.00 $\mu \mathrm{g} / \mathrm{mL}$ ) was prepared by dissolving $5.00 \mathrm{mg}$ of ESL in acetonitrile $(\mathrm{ACN})$ in a volumetric flask, up to a volume of $50 \mathrm{~mL}$. Intermediate solutions of ESL $10.00 \mathrm{~g} / \mathrm{mL}$ and ESL $1.00 \mu \mathrm{g} /$ $\mathrm{mL}$, were prepared by aliquotting $1 \mathrm{~mL}$ of the ESL stock solution and ESL intermediate solution $(10.00 \mu \mathrm{g} / \mathrm{mL})$, respectively, using a volumetric pipette. The solutions were brought to volume with ACN solution in a $10 \mathrm{~mL}$ volumetric flask and stored at a temperature of $4{ }^{\circ} \mathrm{C}$ nominal in polypropylene tubes. BIA 2005 stock solution $(1000.00 \mu \mathrm{g} / \mathrm{mL})$ was prepared by dissolving $10.00 \mathrm{mg}$ of BIA 2-005 in ACN in a volumetric flask, up to a volume of $10 \mathrm{~mL}$. Intermediate solutions of BIA 2-005 100.00, 10.00 and $1.00 \mu \mathrm{g} / \mathrm{mL}$, were prepared by aliquotting $1 \mathrm{~mL}$ of the BIA 2-005 stock solution and BIA 2-005 intermediate solutions ( 100.00 and $10.00 \mu \mathrm{g} / \mathrm{mL})$, respectively, using a volumetric pipette. The solutions were brought to volume with $\mathrm{ACN}$ 


\section{Journal of Bioequivalence \& Bioavailability - Open Access \\ JBB/Vol.1 September-October 2009}

solution in a $10 \mathrm{~mL}$ volumetric flask and stored at a temperature of $4^{\circ} \mathrm{C}$ nominal in polypropylene tubes. The preparation of the internal standard stock solution (IS) consisted of weighing $5 \mathrm{mg}$ of 10,11- dihydrocarbamazepine; then, acetonitrile (500 $\mathrm{mL}$ ) was added to the weighing to give a solution of $10.00 \mu \mathrm{g} /$ $\mathrm{mL}$. The internal standard working solution (ISW) $(100.00 \mathrm{ng} /$ $\mathrm{mL}$ ) was prepared by transferring $5 \mathrm{~mL}$ of stock solution to a $500 \mathrm{~mL}$ volumetric flask and making up to the mark with acetonitrile:water 3:97\% v/v. The method involved the addition of $200 \mu \mathrm{L}$ of human plasma into a $4.5 \mathrm{~mL}$ polypropylene conical tube after vortex mixing for 5 seconds. With a repeater pipette, $500 \mu \mathrm{L}$ of ISW solution $(100.00 \mathrm{ng} / \mathrm{ml}, 10,11$ dihydrocarbamazepine) was added, except to blank samples, and $500 \mu \mathrm{L}$ of acetonitrile:water 3:97\% v/v solution was added to the blank samples. They were vortex briefly. The cartridges (Varian Bond-Elut C18, $100 \mathrm{mg} / \mathrm{mL}$ ) were placed in a $16 * 125$ $\mathrm{mm}$ glass culture tube and the following solutions were added one at a time: $1 \mathrm{~mL}$ of $\mathrm{MeOH}$ (eluting slowly by gravity), $1 \mathrm{~mL}$ of CAN (eluting slowly by gravity) and $1 \mathrm{~mL}$ of acetonitrile:water 3:97\% v/v solution (eluting slowly by gravity). After transferring $600 \mu \mathrm{L}$ of the prepared samples into the cartridges, they centrifuged at $500 \mathrm{rpm}$ for 2 minutes at $22^{\circ} \mathrm{C}$ nominal (low acceleration, high deceleration). The cartridges were then rinsed with $500 \mu \mathrm{L}$ of acetonitrile:water 3:97\% v/v solution and again centrifuged at $1500 \mathrm{rpm}$ for 3 minutes at 22 ${ }^{\circ} \mathrm{C}$ nominal (low acceleration, high deceleration), and at 3000 rpm for 3 minutes at $22{ }^{\circ} \mathrm{C}$ nominal (low acceleration, high deceleration). The cartridges were discarded and the vials were evaporated in a TurboVap at $40{ }^{\circ} \mathrm{C}$ for approximately $10 \mathrm{~min}$ utes. The residue was reconstituted in $1 \mathrm{~mL}$ of mobile phase and was transferred and stored in polypropylene vials at a temperature of $4{ }^{\circ} \mathrm{C}$ nominal until injection. The LC-MS system used in the analysis consisted of a Hewlett Packard series 1100 MS detector and a Waters XTerra ${ }^{\mathrm{TM}} \mathrm{RP}_{18}(150 \mathrm{~mm} \times 2.1 \mathrm{~mm}$ id, $5 \mu \mathrm{m})$ analytical column at $35{ }^{\circ} \mathrm{C}$. The MS detector was operated in API-ES with monitoring masses for ESL, BIA 2-005 and the internal standards of $319.1 \mathrm{amu}, 277.1 \mathrm{amu}$ and $261.1 \mathrm{amu}$, respectively. Calibration curves, over the nominal concentration ranges 10 to $1000 \mathrm{ng} / \mathrm{mL}$ for ESL and BIA 2-005, and a set of quality control (QC) samples were analyzed with each batch of study samples. The QC samples were used to monitor the performance of the assay. The data for the QC samples showed that the overall imprecision of the method, measured by the $\mathrm{CV}$, ranged from $4.3 \%$ to $11.8 \%$, and the inaccuracy of the assay (expressed as the relative error) following extraction and reconstitution ranged from $0.9 \%$ to $3.0 \%$.

ESL and BIA 2-005 were supplied by BIAL (Laboratory of Chemistry, S. Mamede do Coronado, Portugal), and the corresponding internal standard 10,11-dihydrocarbamazepine was supplied by Sigma-Aldrich (St. Louis, MO).

\section{Pharmacokinetic and Statistical Analysis}

The following pharmacokinetic parameters were derived by non-compartmental analysis from the individual plasma concentration-time profiles: maximum observed plasma concentration $\left(\mathrm{C}_{\max }\right)$; time of occurrence of $\mathrm{C}_{\text {max }}\left(\mathrm{t}_{\text {max }}\right)$; area under the concentration-time curve to the last measurable concentration using the trapezoidal method $\left(\mathrm{AUC}_{0-\mathrm{t}}\right)$; area under the concentration-time curve extrapolated to infinity $\left(\mathrm{AUC}_{0-\infty}\right)$; relative percentage of $\mathrm{AUC}_{0-\mathrm{t}}$ with respect to $\mathrm{AUC}_{0-\infty}$; apparent terminal rate constant $(\lambda)$ estimated from a non-linear least-squares regression model, with a minimum of three values at the end of the concentration-time curve; and half-life of elimination $\left(\mathrm{t}_{1 / 1}\right)$. The statistical analysis was performed for each of the 3 groups independently.

Summary statistics of the pharmacokinetic parameters were reported, as appropriate, using the geometric mean, arithmetic mean, standard deviation (SD), coefficient of variation (CV), median, maximum and minimum. The natural logarithm of the parameters $\mathrm{C}_{\text {max }}, \mathrm{AUC}_{0-\mathrm{t}}$, and $\mathrm{AUC}_{0-\infty}$, were also calculated and subjected to the descriptive analysis mentioned above. The elimination parameters $\left(\lambda_{\mathrm{z}}\right.$ and $\left.\mathrm{t}_{1 / 2}\right)$ were not estimated for concentration-time profiles where the terminal log-linear phase has not been reliably characterized.

An analysis of variance (ANOVA) model appropriate for a 2period, crossover design with terms for sequence, subject within sequence, period, and treatment were used to analyze the $\mathrm{C}_{\text {max }}$, $\mathrm{AUC}_{0-\mathrm{t}}$, and $\mathrm{AUC}_{0-\infty}$ of BIA 2-005. The sequence, period and treatment effects were assessed at the 5\% two-sided level. The statistical method for testing bioequivalence was based upon the $90 \%$ confidence interval $(90 \% \mathrm{CI})$ for the Test/Reference geometric means ratio (GMR), for the BIA 2-005 parameters under consideration $\left(\mathrm{C}_{\max } \mathrm{AUC}_{0-\mathrm{t}}\right.$, and $\left.\mathrm{AUC}_{0-\infty}\right)$. Bioequivalence was assumed when the $90 \% \mathrm{CI}$ for the pharmacokinetic parameters under consideration fell within the 80.00-125.00\% bioequivalence range (EMEA/CPMP, 2001; FDA/CDER, 2000).

The statistical and pharmacokinetic analyses were performed by means of a mixed procedure using Kinetic, version 8.00 (application developed at Algorithme Pharma) and SAS version 9.1 (SAS Institute, Cary, NC).

\section{Sample Size and Power Estimation}

Sample size estimation was based on the assumption that the within-subject coefficient of variation of BIA 2-005 $\mathrm{AUC}_{0-8}$ and $\mathrm{C}_{\max }$ was less than 15\% (Maia et al., 2005; Fontes-Ribeiro et al., 2005). Assuming that BIA 2-005 geometric means for the pharmacokinetic parameter under consideration is the same for the pair of treatment alternatives (i.e., the GMR is 1.0), and if $\alpha$ is defined at 0.05 (two-tailed), then 16 subjects in each group would provide at least a $99 \%$ probability that the $90 \%$ CI for the GMR is contained within the $80.00-125.00 \%$ bioequivalence range, and the overall power of the study would be above $80 \%$, as long as the correlation between the pharmacokinetic parameters was non-negative. In order to compensate for eventual drop-outs and to allow balancing for gender, a sample size of 20 subjects in each group was defined.

\section{In Vitro Testing}

Comparative dissolution studies were performed to demonstrate in vitro equivalence between the dissolution curves for the research formulations and the final formulation.

The samples under study were tested with a Varian VK7025 dissolution tester, equipped with a heater/circulator and connected through a peristaltic pump to an UV/Vis Varian Cary 50 spectrophotometer, equipped with a cell position controller. The analytical information was acquired and processed with a Varian Cary WinUV Pharma Software, version number 250 (156), patch 1004 . Apparatus 2 (paddle) was used with a volume 


\section{Journal of Bioequivalence \& Bioavailability - Open Access \\ JBB/Vol.1 September-October 2009}

of $1000 \mathrm{~mL}$ of each one of the three standard buffer solutions (pH 1.20; $\mathrm{pH} 4.50 ; \mathrm{pH} 6.80$ ) at $37.0 \pm 0.5^{\circ} \mathrm{C}$ (Directorate for the Quality of Medicines of the Council of Europe (EDQM), 2006; The United States Pharmacopoeial Convention, 2006). The paddles were operating at $100 \pm 4 \mathrm{rpm}$ for 60 minutes. Each sample was collected through a canula with a $10 \mu \mathrm{m}$ polyethylene flow filter at the end. The detection was performed at $265 \mathrm{~nm}$ with a flow cell pathway of $10 \mathrm{~mm}$. The quantification method has used a standard curve between approximately 0.025 and 1.0 $\mathrm{mg} / \mathrm{mL}$, prepared with not more than $5 \%$ of acetonitrile. The dissolution profiles obtained were compared by means of the similarity factor ( $\left.f_{2}\right)$ (EMEA/CPMP, 2001; FDA/CDER, 2000).

\section{Results}

\section{Population}

Sixty healthy volunteers have been included in the study (30 males and 30 females). The mean \pm SD (range) demographic data were as follows: age 35 \pm 11 (19-54) years, height 168.1 \pm 9.5 (149$188.5) \mathrm{cm}$, weight $69.4 \pm 11.9$ (49.7-97.8) kg, and BMI $24.5 \pm 2.9$ $(18.6-29.3) \mathrm{kg} / \mathrm{m}^{2}$. One female subject was withdrawn from the

\section{ESL $400 \mathrm{mg}$}
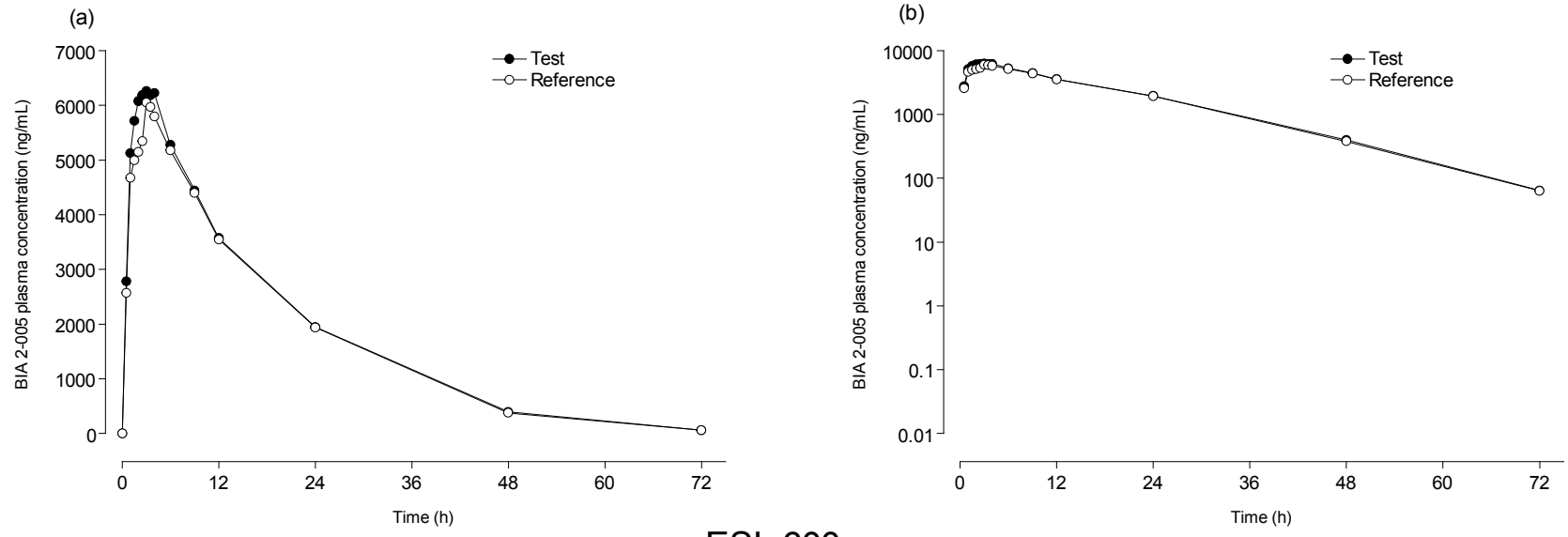

\section{ESL $600 \mathrm{mg}$}
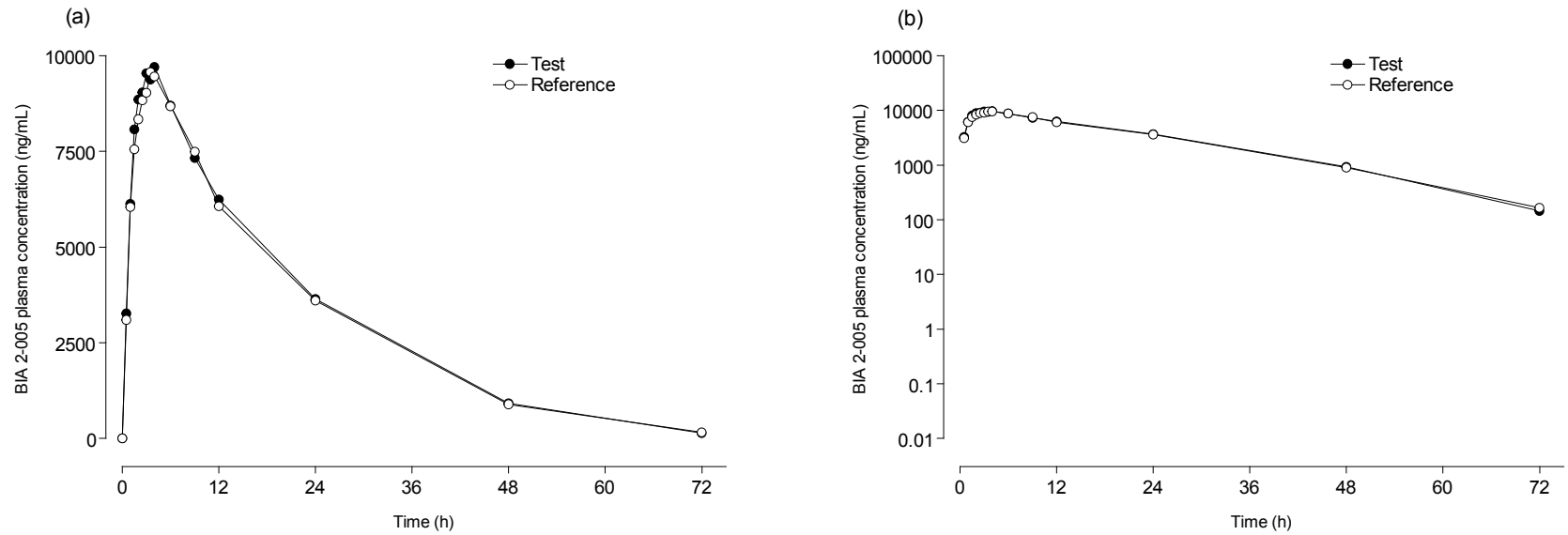

ESL $800 \mathrm{mg}$
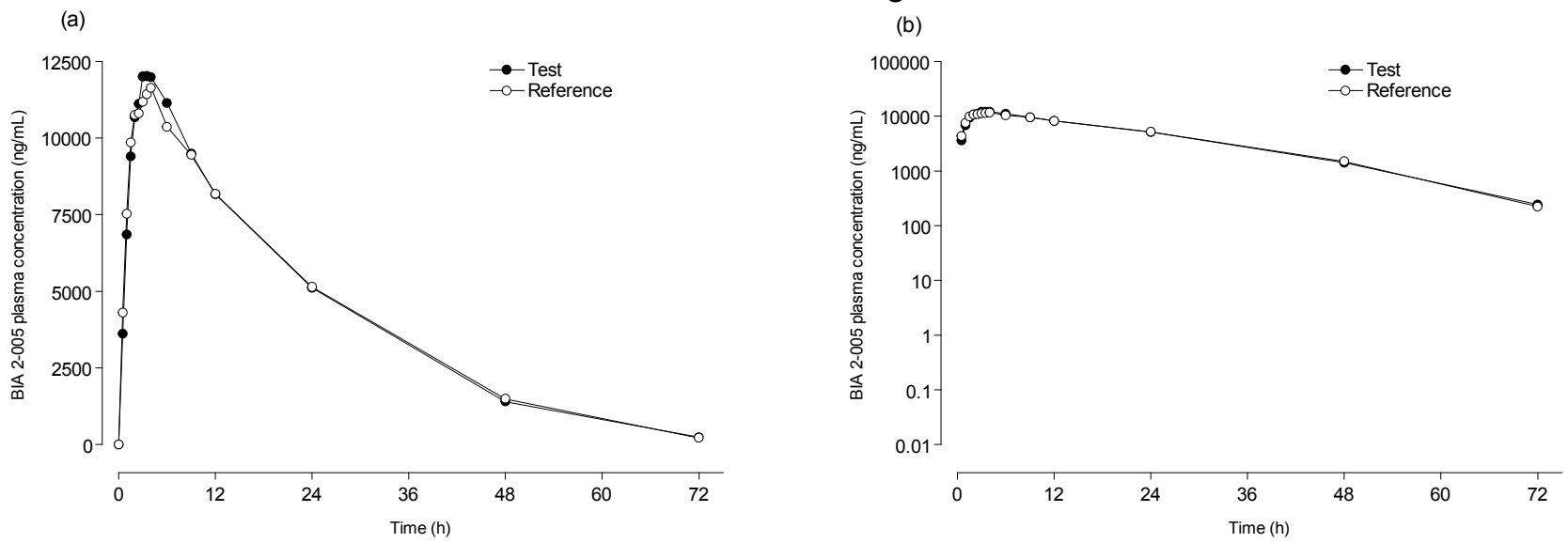

Figure 1: Mean BIA 2-005 plasma concentration-time profiles following oral administration of a single-dose of ESL $400 \mathrm{mg}$ $(\mathrm{n}=20), 600 \mathrm{mg}(\mathrm{n}=19)$ and $800 \mathrm{mg}(\mathrm{n}=20)$, final formulation (Test) and research formulation (Reference). (a) Linear scale; (b) semi$\log$ scale. 


\section{Journal of Bioequivalence \& Bioavailability - Open Access \\ JBB/Vol.1 September-October 2009}

\begin{tabular}{|c|c|c|c|c|c|c|}
\hline \multirow{4}{*}{$\begin{array}{l}\text { BIA 2-005 } \\
\text { Pharmacokinetic } \\
\text { parameters }\end{array}$} & \multicolumn{6}{|c|}{ ESL tablet formulation } \\
\hline & \multicolumn{2}{|c|}{$400 \mathrm{mg}$} & \multicolumn{2}{|c|}{$600 \mathrm{mg}$} & \multicolumn{2}{|c|}{$800 \mathrm{mg}$} \\
\hline & Test & Reference & Test & Reference & Test & Reference \\
\hline & Mean (CV\%) & Mean (CV\%) & Mean (CV\%) & Mean (CV\%) & Mean (CV\%) & Mean (CV\%) \\
\hline $\mathrm{C}_{\max }(\mathrm{ng} / \mathrm{mL})$ & $7108(28)$ & $6660(23)$ & $10725(18)$ & $10405(17)$ & $13186(18)$ & $12768(20)$ \\
\hline $\mathrm{t}_{\max }(\mathrm{h})^{\S}$ & $2.0(44)$ & $2.5(50)$ & $2.5(49)$ & $3.0(43)$ & $3.0(55)$ & $3.0(44)$ \\
\hline $\mathrm{AUC}_{0-\mathrm{t}}(\mathrm{ng} \cdot \mathrm{h} / \mathrm{mL})$ & $125740(23.1)$ & 122134 (22.6) & $219561(18)$ & $215750(21)$ & $294749.1(16)$ & $293960(17)$ \\
\hline $\mathrm{AUC}_{0-\infty}(\mathrm{ng} \cdot \mathrm{h} / \mathrm{mL})$ & $\begin{array}{c}127071.4 \\
(23.5) \\
\end{array}$ & $\begin{array}{c}123419.5 \\
(22.9)\end{array}$ & $\begin{array}{c}222887.1 \\
(18.4)\end{array}$ & $\begin{array}{c}219121.9 \\
(20.9)\end{array}$ & $\begin{array}{c}299320.3 \\
(16.5)\end{array}$ & 299997 (17) \\
\hline $\operatorname{AUC}_{0-t / 0-\infty}(\%)$ & $99(2)$ & $99(2)$ & $99(1)$ & $99(1)$ & $99(1)$ & $98(2)$ \\
\hline$\lambda_{\mathrm{z}}\left(\mathrm{h}^{-1}\right)$ & $0.0783(21)$ & $0.0783(19)$ & $0.0701(24)$ & $0.0701(24)$ & $0.0649(21)$ & $0.0648(20)$ \\
\hline $\mathrm{t}_{1 / 2}(\mathrm{~h})$ & $9.4(29)$ & $9.3(29)$ & $10.4(23)$ & $10.5(25)$ & $11.1(17)$ & $11.1(20)$ \\
\hline
\end{tabular}

${ }^{s}$ For $\mathrm{t}_{\max }$, the median is presented and the statistical analysis is based on a rank-transformation.

Table 1: BIA 2-005 pharmacokinetic parameters following oral administration of a single-dose of ESL $400 \mathrm{mg}(\mathrm{n}=20), 600 \mathrm{mg}$ $(\mathrm{n}=19)$ and $800 \mathrm{mg}(\mathrm{n}=20)$, final formulation (Test) and research formulation (Reference).

\begin{tabular}{|l|l|c|c|c|}
\hline \multirow{2}{*}{$\begin{array}{l}\text { BIA 2-005 } \\
\text { Pharmacokinetic parameters }\end{array}$} & \multicolumn{3}{|c|}{ ESL tablet formulation } \\
\cline { 3 - 5 } & GMR (\%) & $400 \mathrm{mg}$ & $600 \mathrm{mg}$ & $800 \mathrm{mg}$ \\
\hline \multirow{2}{*}{$\mathrm{C}_{\max }$} & $90 \% \mathrm{CI}$ & 105.37 & 102.65 & 104.16 \\
\hline \multirow{2}{*}{$\mathrm{AUC}_{0-\mathrm{t}}$} & GMR (\%) & $99.57 ; 111.52$ & $97.27 ; 108.33$ & $95.44 ; 113.67$ \\
\cline { 2 - 5 } & $90 \% \mathrm{CI}$ & 102.83 & 102.40 & 100.34 \\
\hline \multirow{2}{*}{$\mathrm{AUC}_{0-\infty}$} & GMR (\%) & $99.19 ; 106.61$ & $99.00 ; 105.93$ & $97.85 ; 102.90$ \\
\cline { 2 - 5 } & $90 \% \mathrm{CI}$ & 102.83 & 102.38 & 99.88 \\
\hline
\end{tabular}

Table 2: Final formulation (Test) $v s$. research formulation (Reference) geometric means ratio (GMR) and $90 \%$ confidence intervals (90\% CI) of BIA 2-005 $\mathrm{C}_{\max }, \mathrm{AUC}_{0-\mathrm{t}}$ and $\mathrm{AUC}_{0-\infty}$ following an oral dose of ESL $400 \mathrm{mg}(\mathrm{n}=20), 600 \mathrm{mg}(\mathrm{n}=19)$ and $800 \mathrm{mg}(\mathrm{n}=20)$.

study for pharmacokinetic reasons (missed the two last blood draws). Fifty-nine subjects were analyzed and included in the statistical analysis.

\section{Pharmacokinetic Results}

As the plasma concentrations of ESL were systematically found to be below the limit of quantification, the concentrationtime profiles of the parent drug could not be displayed, nor the pharmacokinetic parameters calculated. Mean plasma BIA 2005 concentration-time profiles, following an oral dose of ESL, research and final formulations, in fasting conditions, were faceto-face compared and the results are depicted in Figure 1, for the three sets under comparison, corresponding to the three tablet strengths $(400 \mathrm{mg}, 600 \mathrm{mg}$ and $800 \mathrm{mg}$ ). The corresponding pharmacokinetic parameters are presented in Table 1.

The GMR and corresponding 90\% CI for the BIA 2-005 $\mathrm{C}_{\max }$, $\mathrm{AUC}_{0-\mathrm{t}}$ and $\mathrm{AUC}_{0-\infty}$ are displayed in Table 2. Bioequivalence criterion was met for all the dosage form strengths, as the $90 \% \mathrm{CI}$ for the pharmacokinetic parameters under consideration were within the $80.00 \%-125.00 \%$ interval. No statistically significant differences between treatments were observed for any of the pharmacokinetic parameters under study.

\section{Tolerability}

ESL was generally well tolerated. During the course of the study, 30 to $40 \%$ of the subjects exposed to each one of the treatments reported at least one adverse event (AE), in a total of $66 \mathrm{AE}, 61$ of which were assessed as possibly drug related (mainly somnolence, reported 25 times, and headache, reported
11 times). Most AEs were mild in severity and resolved without treatment, except two cases of headache which required the use of paracetamol. Not drug-related AEs were 1 case of vessel puncture site pain and 1 case of vessel puncture site haematoma, 1 case of impulsive behavior and 1 case of fatigue. There were no serious $\mathrm{AE}$ or $\mathrm{AE}$ leading to discontinuation.

\section{In Vitro Results}

The dissolution profiles were compared, per strength, Test versus Reference, by means of the similarity factor ( $f_{2}$ ) (EMEA/ CPMP, 2001; FDA/CDER, 2000). The results obtained are presented in Table 3. The slightly lower value obtained at $\mathrm{pH} 6.80$, for the comparison involving the $400 \mathrm{mg}$ strength, is the result of a cone that appears in the bottom of the dissolution vessel, due to the presence of a high content of dibasic calcium phosphate dihydrate.

The results obtained confirmed that, for each pair of formulas under comparison, there was a similar in vitro dissolution profile.

\begin{tabular}{|c|c|c|c|}
\hline \multirow{2}{*}{$\mathrm{pH}$} & \multicolumn{3}{|c|}{$\mathrm{f}_{2}$ for ESL tablet formulation } \\
\cline { 2 - 4 } & $400 \mathrm{mg}$ & $600 \mathrm{mg}$ & $800 \mathrm{mg}$ \\
\hline 1.20 & 53 & 73 & 76 \\
\hline 4.50 & 50 & 50 & 71 \\
\hline 6.80 & 43 & 50 & 60 \\
\hline
\end{tabular}

Table 3: Final formulation (Test) $v s$. research formulation (Reference) similarity factors ( $\mathrm{f}_{2}$ ) for tablets containing $400 \mathrm{mg}, 600$ $\mathrm{mg}$ and $800 \mathrm{mg}$ of ESL, for the different $\mathrm{pH}$ tested. 


\section{Journal of Bioequivalence \& Bioavailability - Open Access \\ JBB/Vol.1 September-October 2009}

\section{Discussion and Conclusion}

The present study aimed to demonstrate that the final tablet formulation of ESL (400 mg, $600 \mathrm{mg}$ and $800 \mathrm{mg}$ ) is bioequivalent to the research formulations used in the phase III pivotal clinical studies. Bioequivalence between other formulations containing ESL, including an oral suspension, had already been investigated and proved (Fontes-Ribeiro et al., 2005).

The results of this study have shown that the three doses of ESL (400 mg, $600 \mathrm{mg}$ and $800 \mathrm{mg}$ ) fulfilled the criteria for bioequivalence between the final and research table formulations. For the three doses, the Test/Reference GMR and corresponding $90 \% \mathrm{CI}$ for $\mathrm{C}_{\max }, \mathrm{AUC}_{0-\mathrm{t}}$ and $\mathrm{AUC}_{0-\infty}$ were all within the acceptance range of 80.00 to $125.00 \%$. This is in line with the previously generated in vitro data, concerning the release profiles of ESL, where the similarity factor $\left(f_{2}\right)$ values have shown equivalence between the formulations under study. Therefore, in clinical terms, it can be assumed that the administration of a specific dose of ESL, by any of the formulations under study, provides identical systemic exposure to BIA 2-005.

ESL was generally well tolerated throughout the course of the study.

In conclusion, bioequivalence between final and research tablet formulations of ESL has been demonstrated.

\section{References}

1. Almeida L, Falcão A, Maia J, Mazur D, Gellert M, et al. (2005) Single-dose and steady-state pharmacokinetics of eslicarbazepine acetate (BIA 2-093) in healthy elderly and young subjects. J Clin Pharmacol 45: 1062-66. " CrossRef » Pubmed " Google Scholar

2. Almeida L, Soares-da-Silva P(2003) Safety, tolerability and pharmacokinetic profile of BIA 2-093, a novel putative antiepileptic agent, during first administration to humans. Drugs R D 4: 269-84.» CrossRef » Pubmed » Google Scholar
3. Almeida L, Soares-da-Silva P (2004) Safety, tolerability, and pharmacokinetic profile of BIA 2-093, a novel putative antiepileptic, in a rising multiple-dose study in young healthy humans. J Clin Pharmacol 44: 906-18. » CrossRef » Pubmed » Google Scholar

4. Benes J, Parada A, Figueiredo AA, Alves PC, Freitas AP, et al. (1999) Anticonvulsant and sodium channel-blocking properties of novel 10,11- dihydro-5H-dibenz[b,f]azepine5-carboxamide derivatives. J Med Chem 42: 2582-87. " CrossRef » Pubmed " Google Scholar

5. Directorate for the Quality of Medicines of the Council of Europe (EDQM) (2006) European Pharmacopoeia 5 supplement 7, 2.9.3. Dissolution test for solid dosage forms, 4805-4814, EDQM, Council of Europe, Strasbourg.

6. EMEA/CPMP (2001) Committee for Proprietary Medicinal Products (CPMP). Note for guidance on the investigation of bioavailability and bioequivalence. CPMP/EWP/1401/98, The European Agency for the Evaluation of Medicinal Products (EMEA), London.

7. FDA/CDER (2000) Center for Drug Evaluation and Research (CDER). Bioavailability and bioequivalence studies for orally administered drug products - general considerations. U.S. Department of Health and Human Services, Food and Drug Administration.

8. Fontes-Ribeiro C, Nunes T, Falcão A, Neta C, Lima R, et al. (2005) Eslicarbazepine acetate (BIA 2-093): Relative bioavailability and bioequivalence of $50 \mathrm{mg} / \mathrm{mL}$ oral suspension and $200 \mathrm{mg}$ and $800 \mathrm{mg}$ tablet formulations. Drugs R D 6: 253-60.» CrossRef » Pubmed » Google Scholar

9. Maia J, Vaz-da-Silva M, Almeida L, Falcão A, Silveira P, et al. (2005) Effect of food on the pharmacokinetic profile of eslicarbazepine acetate (BIA 2-093). Drugs R D 6: 201-06. " CrossRef » Pubmed » Google Scholar

10. The United States Pharmacopoeial Convention (2006) USP 30/ NF25, <711> Dissolution 1: 277-284. 